\title{
RECONFIGURAÇÕES BIOPOLÍTICAS NO GOVERNO DA INFÂNCIA: O DISPOSITIVO DA PSIQUIATRIZAÇÃO
}

\author{
Juslaine de Fátima Abreu Nogueira ${ }^{\mathrm{i}}$
}

\begin{abstract}
Resumo: Neste artigo, indago quais são as condições que têm possibilitado que a psiquiatrização da infância torne-se uma de nossas grandes verdades pedagógicas. Apropriando-me da ferramenta foucaultiana de governamentalidade e biopolítica, a partir da apresentação de fragmentos em forma de dossiê do prontuário de uma criança, teço uma análise sobre o funcionamento do dispositivo da psiquiatrização e de como este engendra um tipo de regulação que, sob uma base identitária, reinsere os corpos desviantes em novos gradientes de normalidade, garantindo que mesmo os que ocupam as franjas da inclusão - os que têm escapado do já estabilizado, decifrável e bem montado script das classificações - sejam abocanhados.
\end{abstract}

Palavras-chave: Dispositivo da Psiquiatrização; Inclusão Neoliberal; Biopolítica.

\section{BIOPOLITICAL RECONFIGURATION IN THE GOVERN OF CHILDHOOD: THE PSYCHIATRIZATION DEVICE}

\begin{abstract}
In this article, I inquire what are the conditions that have enabled childhood psychiatrization to become one of our great pedagogical truths. Taking Foucault's concepts of governmentality and biopolitics, as theoretical tools, upon fragments of a dossier of a child's medical record, I analyze the functioning of the psychiatrization device and how it engenders a type of regulation that, under an identity base, reinsert the deviant bodies in new gradients of normality, ensuring that even those who occupy the fringes of inclusion - those who have escaped the already stabilized, decipherable and well-assembled script of classifications - are snapped up.
\end{abstract}

Keywords: Psychiatrization Device; Neoliberal Inclusion; Biopolitics.

Senhores, as leis e os costumes vos concedem o direito de medir o espírito. Essa jurisdição soberana e temível é exercida com vossa razão. Deixai-nos rir. A credulidade dos povos civilizados, dos sábios, dos governos, adorna a psiquiatria de não sei que luzes sobrenaturais. O processo da vossa profissão já recebeu seu veredito. Não pretendemos discutir aqui o valor da vossa ciência nem a duvidosa existência das doenças mentais. Mas para cada cem supostas patogenias nas quais se desencadeia a confusão da matéria e do espírito, para cada cem classificações das quais as mais vagas ainda são as mais aproveitáveis, quantas são as tentativas nobres de chegar ao mundo cerebral onde vivem tantos dos vossos prisioneiros? (Antonin Artaud, 1925) ${ }^{\mathrm{ii}}$

A princípios del nuevo milênio, cuatro millones de niños son tratados con ritalina por hiperactividad y por el llamado Síndrome de Déficit de Atención, y más de dos 
millones consumen psicotrópicos destinados a controlar la depresión infantil. Estamos frente a un nuevo tipo de capitalismo caliente, psicotrópico y punk. Estas transformaciones recientes apuntan hacia la articulación de nuevos dispositivos microprostéticos de control de la subjetividade con nuevas plataformas técnicas biomoleculares y mediáticas. (Paul. B. Preciado, 2008) ${ }^{\text {iii }}$.

É da construção da narrativa escolar contemporânea da infância inscrita, descrita e produzida em patologias psiquiátricas que este artigo $^{\text {iv }}$ se ocupa. Paulatinamente, a partir dos anos 1990, no Brasil, temos presenciado uma incorporação do vocabulário nosológico advindo da psiquiatria nas vozes da Educação e, a partir das categorias diagnósticas validadas pelas últimas edições do Manual de Diagnóstico e Estatística de Transtornos Mentais (DSM-IV e V), publicados pela Associação Americana de Psiquiatria, bem como a partir do capítulo V do Código Internacional de Doenças - CID-10, que trata da classificação de Transtornos Mentais e Comportamentais, produzido pela Organização Mundial de Saúde, temos visto crianças e jovens amplamente narrados em patologias como Transtorno de Conduta (TC), Transtorno do Déficit de Atenção e Hiperatividade (TDAH), Transtornos de Ansiedade, Transtorno Desafiador de Oposição (TDO), Espectro do Autismo, Dislexia, Transtorno Bipolar, Transtorno Obsessivo-Compulsivo (TOC), dentre muitas outras classificações, muitas das quais, ressalte-se, passam a também compor o assombroso mosaico dos Transtornos Globais do Desenvolvimento (TGD) - cujo carro-chefe é o autismo e seus espectros -, categoria esta que tem sido usada para alargar a identidade dos sujeitos da Inclusão a partir dos mais recentes documentos que norteiam as políticas públicas educacionais brasileiras. Dizendo por outra via, este é um trabalho que se aventura a problematizar este movimento contemporâneo de produção de práticas discursivas, estratégias biopolíticas e tecnologias de governo que têm inserido as crianças como subjetividades portadoras de transtornos mentais e, a partir deste olhar psiquiatrizante, gestado políticas de vida que inscrevem nossas relações educativas nas novas modulações de normalização dadas pelos imperativos de inclusão neoliberal.

Na escola contemporânea, há, pois, um gesto que tem nos ficado demasiadamente fácil: marcar feito-gado, nos corpos infantis, o discurso da corrente reinante da psiquiatria, de vertente norte-americana, que toma todos os sofrimentos psíquicos como quadros psicopatológicos ${ }^{\mathrm{v}}$. Esta perspectiva psiquiátrica, é importante frisar, consolida como verdade à nossa época determinadas formas de entender e tratar os fenômenos de sofrimento psíquico que têm resultado numa estreitada aliança, para lá de produtiva, com a indústria e o mercado farmacêuticos. Desse modo, temos um discurso psiquiátrico reinante, em primeiro lugar, porque posto, soberanamente, como "o científico". Reinante também, em segundo lugar, porque é ele próprio um discurso manhoso, birrento, cheio de reinação: não aceita opositores e bate o pé dizendo sempre, não importa a argumentação, de que é ele quem manda, é ele quem fala em nome da Verdade e da Vida. E assim, na sua manha, traduz-se como a explicação e a reparação (medicalizante) aos males, inquietudes, devaneios, birras, vícios, teimosias e oposições das crianças, pois tais comportamentos, afinal, 
não diriam respeito às relações educativas, mas seriam sinais primariamente de um cérebro em desordem/ em distúrbio. Nessa estratégia, o discurso da psiquiatria (dobrada à neurologia e à farmacologia positiva) vive e reina pelo nosso século, amém. E faz reinar entre nós, na Educação, as classificações médicopsiquiátricas que têm nos permitido nomear as condutas infantis como transtornos mentais e, em nosso também reinante discurso de proteção à infância para torná-la cidadã-incluída, remediá-la.

Pois bem, tornar difícil este gesto que tem ficado tão simples, corriqueiro, banalizado e fácil demais que é discursivizar as condutas das crianças como um caso neuropsiquiátrico é o que requer o empreendimento crítico aqui posto. Desse modo, o movimento de investigação apresentado neste texto faz coro com aqueles que têm se inquietado menos com a inquietude das crianças, mas muito mais com os seguros modos de pensamento e de conhecimento (de uma certa mentalidade) que plantam-se entre nós como discursivizações autorizadas, suficientes e necessárias (verdadeiras, enfim) sobre as errâncias dos infantis. Este trabalho, enfim, se alia aos que tomam esses discursos reinantes como um impasse e não como a resposta tranquilizadora e, até mesmo, desresponsabilizadora à Educação.

Nesse sentido, trata-se de uma pesquisa que menos se preocupa se há psicopatologias verdadeiras ou falsas, se o que está em jogo são anormalidades inventadas (ainda que reconheça a extrema importância de pesquisas neste viés ${ }^{\mathrm{vi}}$ ), senão pretende perseguir quais são as combinações de poder e saber que têm tornado possível inscrevermos os nossos desafios educativos como uma questão do campo da doença mental. Esta investigação nasce da indagação sobre quais condições têm possibilitado que o discurso psiquiatrizante torne-se uma de nossas grandes verdades em Educação, a ponto de encaminharmos os alunos para serem laudados e medicados pelos saberes e práticas neuropsiquiátricos, acionarmos instâncias jurídicas para enredar as famílias "negligentes" a tais procedimentos, criarmos fichas de diagnóstico e encaminhamento no interior das instituições escolares, dentre muitos outros expedientes caudalosos no fazer pedagógico. Esta investigação nasce, enfim, de uma pergunta sobre uma dada mentalidade na qual jazem as práticas que aceitamos e legitimamos, indagação esta que se formula a partir dos engasgos acerca da condução pedagógica de nossa época, da brutalidade feita em preocupação para com a infância, desse empachamento de cotidiano que vai circunscrevendo os corpos infantis nos códigos psiquiatrizantes. Enfim, indagando esta "arte de governar", esta governamentalização que vem explodindo em nossos corpos como população e atingindo-nos individualmente - governo que é político-econômico, mas é também religioso, familiar, médico, jurídico, escolar etc. -, feita em nome da afirmação da vida das pessoas, ou seja, exercendo um poder que pretende "fazer viver", ou seja, operando biopolíticas, o que busco aqui é o gesto de uma crítica radical que põe em questão, na inspiração de Michel Foucault, esta tríade fundamental: as relações entre poder, verdade e sujeito.

Com Foucault, vai-se entendendo que a psiquiatrização e seus desdobramentos de psicofarmacologização e de judicialização da vida são como que sintomas de um regime epistemológico e 
de uma tecnologia de poder que os produzem. É, portanto, este regime epistemológico e esta tecnologia de poder que precisam ser tensionados, problematizados, curtocircuitados. A tarefa é tentar escandir quais condições, algumas recentes, outras nem tanto, mas, de todo modo, singularmente correlacionadas, têm permitido aquilo que estamos sendo, ou seja, têm consentido a psiquiatrização, a psicofarmacologização e a judicialização dos corpos como estratégia de governo da infância na arena educativa de nossa época, cuja força não se pode ver em nenhum outro lugar da história.

Para tanto, realizei um trabalho de investigação em prontuários ${ }^{\text {vii }}$ de crianças - encaminhadas pela escola por queixas de conduta/comportamento (o que, muitas vezes, vinha justificado, primeiramente, sob a roupagem de problemas de aprendizagem) - a centros de avaliação psicopedagógica e atendimento especializado $^{\text {viii }}$. Nestes prontuários, uma vastíssima e refinada narrativa sobre as crianças tem sido produzida, especialmente a partir de sua entrada na escola. São estas discursivizações que me interessaram, a saber, de modo mais específico, as fichas de encaminhamento, relatórios e pareceres oficializados pela escola (os "diagnósticos" dados por professores e equipe pedagógica), bem como o cruzamento disto com laudos/pareceres médicos e psi.

Deparei-me com uma colossal e refinada produção discursiva sobre os corpos infantis que, a partir de sua escolarização, surgem como esse grande personagem da criança-transtornada-laudada e figurada nos liames do aluno-paciente. São verdadeiros dossiês de vidas ínfimas-infames destinadas a passarem sem notação alguma, mas que lampejam e chegam até nós porque ousaram confrontar-se com o poder, debaterse com ele e tensionar seus estratagemas. Trago a este texto fragmentos do prontuário de Steve ${ }^{\mathrm{ix}}$ como representativo da discursivização que ad nauseam se repete acerca dos corpos infantis em nossa época. Apresento-o na forma de Dossiê, para que sejam tomados estes “textos em sua aridez" (FOUCAULT, 2010, p. 204), em sua enfastiação, em seu assombramento, em sua tristeza e em sua banalização. Trago, enfim, estes documentos para que possamos tentar reencontrar, com mais autenticidade, "essas vidas ínfimas que se tornaram cinzas nas poucas frases que as abateram" (FOUCAULT, 2010, p. 204).

E por que Steve? Quando iniciei a pesquisa de campo, um dos primeiros prontuários que abri foi o dele. Reservei-o para ser digitado. Quinze dias depois, soube que Steve fora assassinado. Encontrei-o vivo nesta pesquisa, a tempo de ele conseguir gritar naqueles arquivos, naquela imensidão de pastas timbradas com a logomarca do governo do Estado do Paraná. Agora Steve está morto, à revelia de todo investimento num dado "fazer viver" que o dispositivo da psiquiatrização - estratégia biopolítica que procurarei desenvolver a seguir - realizou sobre seu corpo, corpo este que escandalizou a escola, mas que foi, ele mesmo, cravado por 27 facadas, testemunha da bizarra cumplicidade entre tanta psicofarmacologização e judicialização da vida e a morte. 


\section{O Dossiê de Steve}

Foram muitos os dias assim: o menino saiu do controle. De tão incontrolável, sempre se pensou que era ele quem ameaçava a vida dos outros, inclusive de morte. Ninguém foi capaz de suspeitar o óbvio: que seria ele o assassinado e não o assassino. Pensei que ele era apenas mais um personagem de um dolorido e assombroso prontuário. Dentre tantos enunciados sobre Steve, por exemplo, havia esta reclamação: "Steve é muito repetitivo em seus diálogos, possui temas de interesse como filmes e, se permitido, fala o tempo todo nestes assuntos [...]". Havia uma criança que gostava de filmes e queria conversar sobre cinema, mas a escola tomava isto como inadequado e afrontoso. Pensei que Steve era apenas uma história real, que de tão real, era mais um entre tantos e nunca sairia desta realidade. Reencontrei-o em Mommy, filme de 2014, do cineasta canadense Xavier Dolan. Foi como descobrir que o menino não havia morrido. Explodia vivo na ficção. Foi por isso que o renomeei "Steve", um jovem de 15 anos, diagnosticado com TDAH. A personagem-mãe foi quem me contou assim: "Porque a vida com Steve é como um jogo. Ou você tem sorte. Ou você não tem. Steve é violento. É um bom garoto, cheio de carisma, mas quando ele explode, a coisa fica feia. E, um dia, as coisas vão sair de controle"x. Sim, a morte foi o incontrolável. Eis alguns fragmentos da narrativa escolar sobre Steve:

\section{Agosto/2008 - Fragmento de Relatório de Avaliação Psicoeducacional. Steve tinha 11 anos.}

[...] Histórico Pessoal: As informações foram fornecidas em entrevista com a avó materna. Steve é o segundo filho numa prole de 3. A mãe estava com 19 anos quando engravidou sem planejamento e não havia consanguinidade entre os pais. [...] Gestação foi tranquila. O parto foi a termo, normal [...]. Faz uso de medicação para ficar calmo (metade à noite), mas a avó não recorda o nome. [...] Fez atendimento psicológico, mas parou. Consultou com neurologista e está sendo acompanhado. Quanto ao relacionamento, a avó diz que Steve se dá bem com os pais e avó, mas [...] é muito agitado. Faz amizades com facilidade, mas briga muito [...].

[...] Conclusão Diagnóstica: Demonstra estar no processo de apropriação do conhecimento compatível com a série em que se encontra. Diagnóstico de Transtorno de Déficit de Atenção e Hiperatividade e Transtorno Desafiador Opositor, fazendo tratamento medicamentoso. [...]

Encaminhamentos: Recomenda-se que o aluno continue frequentando o Ensino Fundamental com atendimento em contraturno na Sala de Recursos em Condutas Típicas. Sugere-se a retomada no atendimento psicológico (segundo a escola, tem comportamento opositor e recusa frente a atividades escolares). Sugere-se continuidade no atendimento neurológico. 
Setembro/2009 - Parecer Escolar assinado pela pedagoga e pela professora da escola. Steve tinha 12 anos.

[...] Quando está presente, o comportamento de Steve é bastante imprevisível. Há dias em que chega e imediatamente abre o caderno para realizar as atividades; há outros, porém, em que nem sequer senta em seu lugar - passeia pela sala, provoca os outros alunos, vai até à janela e mexe com quem passa e, quando tem a atenção chamada, responde desrespeitosamente. [...] Se tem atenção exclusiva da professora, cumpre as tarefas pedidas. Quando a atenção é dividida com o restante da turma, ele deixa de participar novamente.

[...] Por conta do que foi exposto, seu desempenho tem sido insatisfatório. Não demonstra grandes dificuldades de aprendizagem, mas apresenta pouco interesse pela escola e parece não perceber seu valor. Também não demonstra estar preocupado com sua situação escolar (faltas excessivas, muito conteúdo para recuperar e quase todas as provas não feitas). Parece interessar-se pela Matemática. [...] não tem dificuldades para se socializar. É extrovertido, carismático e diverte as crianças com suas brincadeiras. [...] Gosta de jogos, mas tem muita dificuldade em aceitar a derrota.

\section{Atestado Médico-Psicológico - 03/12/2009 - assinado por psiquiatra e psicóloga}

Secretaria Municipal de Saúde - Ambulatório de Saúde Mental. Steve tinha 12 anos.

Atesto para os devidos fins que o aluno Steve [...] apresenta, no momento, Transtorno do Comportamento Mental compatível com o CID 10F e 93.9. Está medicado com Risperidona 2,0 mg. Participa dos Grupos Terapêuticos (crianças, familiares, psiquiatra, psicóloga e professoras de Condutas Típicas) com assiduidade.

\section{0 de dezembro de 2010 - Parecer Escolar assinado por professora e pedagoga. Steve tinha 13 anos.}

Após um período de muito desinteresse, excesso de faltas e comportamento relativamente rebelde em sala, o Steve apresentou uma melhora considerável. Mostrou-se mais interessado e preocupado com sua aprovação. Realizou as atividades solicitadas para a recuperação de suas notas e foi aprovado. Ao receber a notícia da aprovação, demonstrou muita alegria e orgulho. [...] O Steve precisa sentir que há quem se preocupe com ele, tanto na escola quanto em casa; precisa de alguém que o corrija quando errar, mas que não deixe de elogiá-lo e incentivá-lo quando ele tomar atitudes corretas.

\section{3 de dezembro de 2010 - Parecer Descritivo da Sala de Recursos de Condutas Típicas. Steve tinha 13} anos.

Durante este semestre, pode-se observar que Steve teve seu rendimento escolar rebaixado, especialmente no terceiro bimestre. [...] 
Steve deve permanecer em Sala de Recursos TGD e terapia psiquiátrica, especialmente por estar indo para a 5. a série e muitas mudanças surgirão nesta nova fase. É importante que seja feita uma mediação no início do ano com os professores que trabalharão com ele no sentido de comunicar e alertá-los para o olhar diferenciado em relação a Steve.

\section{6 de maio de 2011 - Relatório Escolar assinado por professora. Steve tinha 13 anos.}

Steve se mostra muito agitado em sala de aula e fora dela. Sente necessidade de chamar atenção de todos o tempo todo, principalmente da professora, demonstrando muita carência afetiva. Possui muita dificuldade em seguir regras e tenta o tempo todo achar formas de fugir destas.

Possui dificuldade em se concentrar, necessitando constantemente da retomada de atenção. Dificilmente conclui as atividades iniciadas. Quando solicitado para fazer alguma atividade, sempre diz não saber fazer [...]

Steve é muito repetitivo em seus diálogos, possui temas de interesse como filmes e, se permitido, fala o tempo todo nestes assuntos, o que acaba irritando os demais colegas.

\section{9 de junho de 2011 - Ficha de Acompanhamento Escolar assinada por vários professores, pedagogas, diretora e representante da Secretaria de Educação. Steve tinha 13 anos.}

A pedagoga colocou que há alguns profissionais que estão realizando o curso do Poeta $^{\mathrm{xi}}$ para entender a inclusão. Relata que Steve não está tão mal na aprendizagem. A coordenadora da Secretaria de Educação coloca que, diante da lei, Steve ainda não é tido como incluso (pois não tem laudo oficial com diagnóstico, apenas um atestado), mas permanece [nos atendimentos] até o presente momento. Esta explica que Steve recebe atendimento psicológico e pedagógico e, mensalmente, com a psiquiatra [...].

[...] A pedagoga relata que [...] na sala há 3 TDAH e 2 sem diagnóstico, mas que apresentam dificuldade. A professora de Matemática diz que Steve é agitado [...], não abriu o caderno neste bimestre [...]. Tem vindo para a escola sujo e com mau cheiro (higiene). O professor de Educação Física diz que Steve é agressivo com os colegas [...]. Tem alguns colegas que não querem fazer atividade com ele, não o querem no time e Steve acaba ficando sozinho. Mesmo quando está na sala, fica na janela, ameaça os colegas como matar [...]. Outro professor disse que o aluno ameaçou jogar o computador na cabeça.

[...] A diretora coloca que todas as vezes que é necessário conversar, chora. Fazem os combinados, ela pede a colaboração e ele volta para sala. O professor de Geografia diz que houve uma interrupção na vida dele, se perdeu e usa o enfrentamento. O referido professor colocou que não concordou com o encaminhamento, mas compreende e a professora de Português disse que o orientou, mas não teve ação para a organização. A psicóloga diz que a família precisa assumir a responsabilidade e acolhê-lo. A 
coordenadora da Secretaria de Educação coloca que deverá comunicar o Conselho em grupo e solicitar a visita da Assistente Social para encaminhamentos posteriores. A escola deverá encaminhar relatório de faltas e atitudes. [...]

09 de junho de 2011 - Ata Escolar assinada por vários professores, pedagogas, diretora e representante da Secretaria de Educação. Steve tinha 13 anos.

[...] Estavam presentes na reunião a coordenadora da Secretaria de Educação, a psicóloga, a pedagoga e professora do Centro de Atendimento Especializado em Transtorno Global do Desenvolvimento - CAEE-TGD, a diretora e a pedagoga da escola, bem como os professores envolvidos no processo ensinoaprendizagem do aluno.

[...] A pedagoga relata que o aluno se recusa a conversar sobre os problemas que ele vem apresentando e quando é chamado na sala, se recusa a sair e fala palavrões. A professora de Matemática diz que tem mais três alunos que também recebem atendimento neurológico e fazem parte do Programa Poeta, mas não são tão graves como o Steve. A coordenadora da Secretaria de Educação fala que estes alunos possivelmente estão acompanhados de medicamento, motivo pelo qual os professores têm conseguido trabalhar com estes alunos. Já o Steve, por não estar cumprindo adequadamente os encaminhamentos com terapia e atendimento no TGD, tem maior dificuldade tanto na aprendizagem como na relação interpessoal. [...] O professor de Educação Física relata que [...] o aluno não aceita regras, é difícil, surta quando é contrariado, grita, chora por qualquer coisa, diz que vai matar. Também há agressões físicas. Fala "vou te dar um tiro e chamar meus amigos". [...] A assistente social vai fazer visita in loco e dará retorno. A escola fará encaminhamento ao Conselho Tutelar. O CAEE-TGD encaminhará também relatório ao Conselho Tutelar [...].

10 de Junho de 2011 - Encaminhamento do Centro de Atendimento Educacional Especializado - Transtorno Global do Desenvolvimento endereçado ao Conselho Tutelar. Assinam coordenador do CAEE -TGD, pedagoga, professora e psicóloga. Steve tinha 13 anos.

O aluno Steve foi avaliado pela Equipe de Avaliação Psicoeducacional nos dias 07/08/08 e 14/08/08, com encaminhamento para continuidade no Ensino Regular e atendimento em contraturno em Condutas Típicas, hoje Centro de Atendimento Educacional Especializado - Transtorno Global do Desenvolvimento (CAEE-TGD); além destes, também sugeriu-se retomada nos atendimentos psicológicos (segundo a escola tinha comportamento opositor, recusa frente a atividades escolares) e continuidade no atendimento neurológico.

[...] De acordo com relatos da escola, o aluno encontra-se em situação de vulnerabilidade social com agravamentos rápidos e a família se mostra negligente e omissa em relação ao filho. 
A psiquiatra solicitou avaliação do CAPS-AD ${ }^{\text {xii }}$. Segundo a psicóloga, no final do ano passado, foi realizado um primeiro atendimento no ambulatório do CAPS, mas não foi dado continuidade.

Diante da situação apresentada, solicitamos deste Conselho acompanhamento em relação aos atendimentos do CAPS-AD e medidas cabíveis ao caso.

\section{1 de Setembro de 2011 - Encaminhamento assinado por Assistente Social endereçado à Escola.} Steve tinha 14 anos.

[...] encaminhamos o Steve e sua irmã para o CRAS ${ }^{\text {xiii }}$ com o objetivo de inseri-los em programas que beneficiem a família, o desenvolvimento deles e os retirem da "situação de rua" em que se encontram.

\section{2/03/2014 - publicação na Imprensa local. Steve tinha 16 anos.}

Adolescente é morto com 27 facadas em ponto de ônibus

Um adolescente de 16 anos de idade foi brutalmente assassinado na madrugada de sábado $\left(1 .^{\circ}\right)[\ldots]$. Steve foi encontrado em um ponto de ônibus da rua onde morava com 27 facadas.

O crime ocorreu por volta das $5 \mathrm{~h}[\ldots .$.$] . Steve levou facadas no pescoço, nas costas e nos braços. De$ acordo com informações obtidas pela polícia no local, ele era usuário de drogas e estaria no ponto de ônibus fumando maconha.

A Delegacia [...] está aguardando depoimentos dos familiares para chegar à autoria do crime. O corpo do adolescente foi encaminhado ao Instituto Médico Legal (IML)

\section{A passagem para o dispositivo da psiquiatrização}

Se a produção da infância - e todos os seus contornos, a saber, a arquitetura da criança normal e a criança anormal - coube num projeto da Modernidade, parece haver um movimento descontínuo datandose desde os últimos anos do século XX, que tem acionado sobre os corpos infantis, de maneira mais refinada e abrangente, um processo de (a)normalização que menos tem a ver com a ideia da criança com deficiência ou com limitações cognitivas, mas que se refere muito mais à noção de criança com "problemas de conduta"/ de comportamento. Tal deslocamento na noção de (a)normalidade tem sido possível porque, ao que parece, estão em jogo recontextualizações e entrecruzamentos de diferentes regimes discursivos psi pactuados historicamente no campo pedagógico, uma vez que as certezas dos preceitos-psi ancorados na psicologia do desenvolvimento, os quais forneceram a tônica de nossa dizibilidade e visibilidade sobre as crianças e sobre as práticas pedagógicas ${ }^{\mathrm{xiv}}$, somam-se, agora, mais do nunca, aos preceitos-psi da psiquiatria 
hegemônica de nossa época, provocando uma espécie de modulação do dispositivo psi na educação que, do tom psicologizante, por assim dizer, passa para a orquestração psiquiatrizante.

As discursivizações psi no campo da Educação - historicamente pautadas no atravessamento de saberes diversos como o da psicologia do desenvolvimento, da epistemologia genética piagetiana ou até mesmo de certas apropriações da psicanálise freudiana - entrecruzam-se, agora, com um agigantamento da gramática da psiquiatria em torno do corpo infantil no território educacional escolarizado como um todo, extrapolando a sua já solidificada presença nas demarcações da chamada Educação Especial. Exatamente aqui, faço a suspeita de que entra em jogo, na escola contemporânea, uma reconfiguração que vocifera, agora, uma passagem, por assim dizer, do regime de psicologização dos corpos ao de psiquiatrização dos corpos, sempre em nome do projeto normalizador de regulação das condutas infantis que fabricaram e animaram o surgimento da infância. A aposta é que há uma descontinuidade importante aí, uma vez que o processo de psiquiatrização dos sujeitos escolares em nossa época encontra-se com condições históricas bastante novas: a da era do cérebro/supremacia do radical neuro, a da farmacologização dos corpos e a exacerbação da judicialização da vida, cujos elos conectam as práticas de inclusão funcionando a partir da governamentalidade neoliberal.

Dizendo de outro modo, a ideia de passagem não quer dizer, em hipótese nenhuma, substituição ou sobreposição dos saberes da psicologia pelos da psiquiatria, senão que há, cada vez mais, uma imbricação destes campos nas práticas biopolíticas que transpassam a educação escolarizada. Arrisco fazer uma (perigosa) distinção nas discursivizações psi no interior da arena educativo-escolar para poder defender que - somada às explicações organicistas, à gestão do risco social e ao deslocamento do ensino para a aprendizagem, pressupostos que historicamente vêm selando o dispositivo da psicologia na pedagogia (COUTINHO, 2008) - a noção de uma psiquiatrização da educação parece-me bastante produtiva. Defendo que há um dispositivo da psiquiatrização porque considero que é justamente na psiquiatria contemporânea que há uma especial sintetização de três grandes movimentos-chave nos processos de governamento em nossa época gerindo políticas sobre a vida das populações: 1) a prevalência da ciência do cérebro (o camponeuro) como paradigma central na construção dos nossos jogos de verdade; 2) a farmacologização dos corpos, fundamentalmente no que concerne ao controle da alma/da psique; 3) a judicialização da vida. São estes três fenômenos, como peças centrais do dispositivo da psiquiatrização que, então, darão sustentação à realização desta imensa finalidade: a possibilidade de inclusão das subjetividades que se localizam nos franjamentos de inteligibilidade dos corpos.

Os processos de inclusão têm visto escaparem de suas garras inúmeras subjetividades. Há sempre os que fazem morada nas franjas da grade de compreensão dos corpos para bem estarem incluídos. É isto o que tem acontecido, por exemplo, a pessoas trans que, para serem reconhecidas como sujeitos de direito e participarem dos processos socioeducacionais inclusivos, têm de passar pela maquinaria da 
psiquiatrização de seus corpos. Estão inseridas também crianças e jovens que não podem ser encaixados como um caso dos paradigmas clássicos da deficiência, mas cujas condutas escorrem das amarras da normalidade. É isso: a normalidade não está dando conta das condutas, do fato dos comportamentos que escapolem. Para estes que sobram, o dispositivo da psiquiatrização tem se mostrado uma potente estratégia normalizadora.

A entrada em cena do dispositivo da psiquitrização é constitutivo de uma governamentalidade que, nos ditames neoliberais, tanto tem nos possibilitado inscrevermos os corpos infantis e os desafios fervilhados na educação escolarizada dentro do campo da doença mental, quanto tem nos possibilitado conjugar uma sintaxe política - feita em nome do "fazer viver" - pela qual se tramam ações do Estado, de Instituições, de Organizações e Movimentos Sociais e do Mercado, fabricando novos modos de governo da infância, agora entendida nos imperativos da inclusão. Desse modo, empresto o termo dispositivo que, na acepção foucaultiana, demarca:

[...] em primeiro lugar, um conjunto decididamente heterogêneo que engloba discursos, instituições, organizações arquitetônicas, decisões regulamentares, leis, medidas administrativas, enunciados científicos, proposições filosóficas, morais, filantrópicas. Em suma, o dito e o não-dito são elementos do dispositivo. $\mathrm{O}$ dispositivo é a rede que se pode estabelecer entre esses elementos. Em segundo lugar, [...] entre estes elementos, discursivos ou não, existe um tipo de jogo, ou seja, mudanças de posição, modificações de funções [...]. Em terceiro lugar, entendo dispositivo como um tipo de formação que, em um determinado momento histórico teve como função principal responder a uma urgência (FOUCAULT, 2002, p. 244).

Entendo, assim, que há um conjunto de elementos - discursivos e não-discursivos - que têm acionado, como nunca, nos domínios da escolarização este dispositivo da psiquiatrização. Na urgência da governamentalidade neoliberal, o dispositivo da psiquiatrização tem feito surgir, no Brasil, um enorme conjunto de proposição legislativas. Disto tem resultado, por exemplo, a fabricação de leis, a produção de uma abundante engenharia terapêutica e a sustentação da medicação das crianças, ancorando a expansão da indústria dos psicofármacos. Não raro e sem nenhum escrúpulo, pois gesta-se um entendimento de legítima parceria entre ONGs, Estado e Mercado, aparecem grandes representantes das indústrias farmacêuticas - em especial aqueles fabricantes das drogas referentes ao tratamento medicamentoso dos transtornos mentais - como apoiadores das iniciativas biopolíticas ${ }^{\mathrm{xv}}$.

Durante o período de pesquisa de campo, mergulhada naqueles prontuários todos, presenciei muitas vezes a angústia de profissionais de centros de avaliação psicopedagógica e atendimento especializado (professores, psicólogos, fonoaudiólogos, fisioterapeutas, terapeuta ocupacionais e psiquiatras) diante da cada vez mais crescente demanda das escolas por encaminhar seus alunos para serem avaliados e diagnosticados. A angústia se devia ao trabalho acumulado pela farta e abundante lista de espera. A angústia 
se devia porque a reivindicação por avaliações vinculadas aos diagnósticos psiquiátricos estava vindo também das creches, a ponto da Secretaria de Educação estar estruturando uma "equipe" especificamente para começar a avaliar crianças da Educação Infantil e não apenas as do Ensino Fundamental, sob o argumento de que quanto antes se identificassem os "problemáticos", mais cedo poderiam se realizar as intervenções e diminuir os riscos. A angústia se devia porque há uma tácita, mas voraz, expectativa escolar de que as avaliações confirmem diagnósticos já dados, "informalmente", pelos próprios professores que se inconformavam caso os relatórios avaliativos revelassem "que a criança não tem nada". A psiquiatrização dos corpos é uma fábrica poderosa que os produz bem antes da "certificação oficial”, ou seja, o laudo médico-psi. E, diante disto, o mais grave: a regra do jogo àqueles profissionais todos parece ser, de modo disparatado e estapafúrdio, realmente produzir algum diagnóstico "oficial" para que as crianças possam, quem sabe, receber algum acolhimento na escola, uma vez que somente sob algum diagnóstico repousado no discurso de verdade da psiquiatria hegemônica que se mobiliza algum esforço da escola para conseguir olhar alguma singularidade. Em outras palavras, o diagnóstico e o laudo psiquiátricos, o "rótulo" patologizador e a identidade DSMizada estão colocados como a única chance de pertencerem à escola e à sociedade esses corpos indecifráveis e transbordantes, que não cabem nas identidades deficientes e nem em nenhuma patologia classicamente reconhecível, estes que ainda escapam, as figuras da abjeção contemporânea.

Os diálogos informais, a observação de como os discursos orais circulavam e o confronto de tudo isso com as narrativas escritas dos prontuários foram mostrando-me que as condições de produção dos relatórios, dos laudos, dos pareceres, das fichas de encaminhamento e acompanhamento, em suma, as condições de produção de toda aquela maquinaria documental sobre os corpos das crianças eram manifestações de inscrições discursivas, ou seja, de jogos de verdade dos quais parecem não poder escapar a posição-sujeito de professores, da equipe multidisciplinar, de médicos, de psicólogos, de todos o profissionais parte da chamada rede de proteção (as instâncias jurídicas: conselheiros tutelares, juízes, promotores do Ministério Público). Quase todos, de seus lugares institucionais, nada mais fazem do que entrar no jogo discursivo posto, movendo-se na confluência das verdades psi-médico-jurídica hegemônicas pelas quais seus próprios corpos são interpelados em nossa governamentalidade neoliberal. Quase todos fazem funcionar o dispositivo da psiquiatrização como um lugar de julgamento dos corpos infantis que já vêm justificados na virtualidade da periculosidade, anunciando uma dada situação de "risco social".

E o que parece ser, de fato, este risco? O risco da delinquência, o risco de não se fazer um corpo empregável $^{\text {xvi }}$, o risco de não pertencer à posição de consumidor, o risco de afrontar o sistema cisheteronormativo, em síntese, o risco de não estar, enfim, viabilizado moral e economicamente (SIERRA, 2013). Entendo que a noção de risco cravada nos corpos das crianças infames da escola está profundamente conectada ao que Jamil Cabral Sierra conceitua como vida viável, ou seja, são aquelas vidas ainda "não 
ajustadas aos processos de classificação, correção e normalização"; são os corpos não cabíveis numa normatividade "que institui a lógica identitária como recurso à inclusão na esfera jurídica, social e educacional"; são corpos não conciliados à prescrição das "práticas sexuais e afetivo-amorosas [...] corretas, honradas, saudáveis, seguras e aceitáveis", são vidas, enfim, não harmonizadas ao "projeto de utilidaderentabilidade que a ordem do consumo e do trabalho neoliberais apregoam como necessárias ao projeto de consolidação do sujeito de direito" (SIERRA, 2013, p. 68-69).

Como expurgo daquilo que este corpo pode oferecer de perigo é que é preciso, então, laudá-lo. É preciso submetê-lo a uma série de exames cujos resultados decalcam as mesmas vulgatas e, no fim, oferecem-lhe um pretenso diagnóstico redentor: uma identidade DSMizada, categorizada no CID. É a teatralidade monótona e previsível desses documentos que, legalmente, ampararão os corpos infantis na escola contemporânea e que vão justificar seu direito de pertencer, seu direito de participar, seu direito, enfim, de estar incluído neste espaço.

É, então, esta arena de saber-poder, constituindo o verdadeiro de nossa época, que me fez suspeitar do funcionamento do argumento central que trago a este artigo: é, pois, a compulsoriedade de incluir os corpos e condutas desviantes aquilo que rege a grande condição de possibilidade do aparecimento deste fenômeno de psiquiatrização dos sujeitos escolares, ampliando a fome moderna de normalização. Em nossa atualidade, corpo normalizado é o corpo que está incluído. A inclusão, portanto, é o grande imperativo (LOPES, 2009; LOPES e VEIGA-NETO, 2011); psiquiatrizar é estratégia. Não é a psiquiatrização, por óbvio e a princípio, o que normaliza, mas há um dispositivo da psiquiatrização que, paradoxalmente, ao anormalizar, é o que permite garantir a ação das biopolíticas inclusivas, pois atua na captura da diferença, orquestrando o reajuste dos corpos e os reinserindo em novas normalidades. Em outras palavras, o dispositivo da psiquiatrização é o que contribui e garante, via escola, na lógica das biopolíticas neoliberais, uma boa parte dos processos de inclusão, uma vez que permite abocanhar as subjetividades que habitam as franjas da inclusão, especialmente aquelas que têm escapado do já estabilizado, decifrável e bem montado script das classificações.

Maura Corcini Lopes e Alfredo Veiga-Neto (2011) mostram que a inclusão, em seu paradigma neoliberal, refere-se "a um número cada vez maior de indivíduos a incluir" (p. 122) e, neste sentido, urge problematizar quem são estes sujeitos aspirantes da inclusão, quem são estes que estão entendidos como os excluídos, que estão compreendidos, num jogo binário, no lugar desse ainda "outro da inclusão". Pareceme que este "outro da inclusão" tem sido ocupado, em muito, por aqueles que, estranhamente, ainda insistem escapar das incontestáveis benesses das garras inclusivas de nossa atualidade. Nos insights de Butler (2001), arrisco dizer que a psiquiatrização como estratégia de inclusão atinge enormemente a estes a quem a filósofa tem chamado de "corpos abjetos", esses corpos que não importam, que habitam a ininteligibilidade e que, portanto, ainda não poderiam, na lógica binária da Representação/da Identidade, 
ter uma existência reconhecida e legítima.

É preciso, portanto, afastar-se desse binarismo. Por isso, Maura Lopes e Veiga-Neto também ressaltam que “a inclusão não é 'boa' por si mesma; além disso, ela não é, necessariamente, o outro da exclusão. Do mesmo modo, pode-se compreender que muito frequentemente inclui-se para excluir, isso é, faz-se uma inclusão excludente" (2011, p. 123), o que nos leva a considerar, assumindo a argumentação e a grafia proposta pelo Grupo de Estudo e Pesquisa em Inclusão (Gepi/CNPq/Unisinos), que o que tem estado em jogo, de fato, é uma in/exclusão:

Grafar in/exclusão aponta para o fato de que as atuais formas de inclusão e de exclusão caracterizam um modo contemporâneo de operação que não opõe a inclusão à exclusão, mas as articulam de tal forma que uma só opera na relação com a outra e por meio do sujeito, de sua subjetividade. [...] Dessa forma marcadamente relacional, a in/exclusão se caracteriza pela presença de todos nos mesmos espaços físicos e pelo convencimento dos indivíduos de suas incapacidades e/ou capacidades limitadas de entendimento, participação e promoção social, educacional e laboral (LOPES e VEIGA-NETO, 2011, p. 130-131).

Pelas articulagens da in/exclusão, evidencia-se o quão inócuo é insistir num debate que coloca a questão da inclusão num mero posicionamento de matriz maniqueísta/dicotômica, que facilmente reduz qualquer problematização da inclusão como uma automática aceitação das práticas historicamente excludentes. Assim, faz-se necessário mostrar como a inclusão tem sido naturalizada como uma condição revolucionária, progressista e humanista em si mesma, apagando-se a racionalidade política e a moral neoliberal que a tem orquestrado, de forma que, compulsoriamente, ela se coloca como dever a ser assumido por todos que defenderiam uma sociedade democrática e um estado de direito.

\section{Algumas considerações finais: conversações em aberto}

Tentei desenvolver o argumento de que nossa época tem feito funcionar o que chamei de dispositivo da psiquiatrização e de que modo tal dispositivo tem reassentado o regime epistemológico da normalidade na escola e operado como uma estratégia a serviço das tecnologias de governamento da infância na racionalidade biopolítica neoliberal. Desta forma, na espessura de um dossiê que traz toda uma discursivização que azeitou o governo sobre o corpo de Steve (este Steve que é também tantos outros da infância contemporânea), procurei fazer uma movimento de análise que argumenta como a psiquiatrização dos corpos escolarizados engendra um tipo de regulação das condutas infantis que possibilita melhor abarcar a população das crianças numa política identitária de sujeito de direito. É nesta condição - como sujeito de direito - que os corpos infantis poderão participar, inclusive, dos processos de 
psicofarmacologização e de judicialização para, assim, paradoxalmente, ao serem anormalizados, poderem estar no alvo da Inclusão e, porque incluídos, serem normalizados. Há, por certo, a localização de um forte engasgo e um ponto nodal neste argumento, ao apostar que é a psiquiatrização aquilo que, em grande medida, tem permitido os exercícios inclusivos das sociedades neoliberais, este território escorregadio e repleto de armadilhas de um tipo de governamentalidade e de estratégias biopolíticas que têm repousado na verdade inquestionável do sujeito de direito - a verdade numa matriz jurídica e não, necessariamente, ética - encarcerada nos essencialismos identitários.

A discursividade dos prontuários foram apontando-me que, nas reconfigurações das técnicas biopolíticas no governo do corpo infantil, estão em jogo algumas operações profundamente interdependentes: a) o dispositivo da psiquiatrização está fortemente articulado à entrada da criança no espaço-tempo escolar, fazendo aparecer a personagem-criança nomeada em inúmeros transtornos mentais, fabricando os novos infames da escola: os transtornados-laudados-psicofarmacologizados; b) a construção e mediação de uma experiência de si tem passado pela condução da conduta como questão neuro-orgânica e, assim, por uma tecnologia do eu pautada no corpo regulado, controlado e disciplinado psicofarmacologicamente, cuja aspiração final seria uma morna harmonia escolar que nos livraria dos transbordamentos, ajoelhando os corpos a uma dada tranquilidade da resiliência. Assim, a textualidade dos documentos vai apontando-nos a fabricação de corpos que, nas ações farmacobiopolíticas, vão dando as pistas sobre o adoecimento da vontade e o aparecimento de existências que, embora tão jovens, surgem empalidecidas, opacas, indiferentes e mumificadas; c) o dispositivo da psiquiatrização tem promovido a oscilação da infância em uma nova categoria: a do aluno-paciente que, nos engendramentos da governamentalidade neoliberal, fundamentalmente sustentada pelos imperativos de inclusão e da gestão do risco, entra na maquinaria do poder farmacológico, azeitando investimentos biopolíticos em torno da medicalização (ancorando a expansão da indústria dos psicofármacos) e da judicialização da vida (através do Conselho Tutelar, Ministério Público, outras instâncias de assistência social que compõem a chamada Rede de Proteção); d) o dispositivo da psiquiatrização tem aniquilado não apenas os corpos das crianças e dos jovens, mas também a capacidade do pensamento de professores, diretores, pedagogos, médicos, conselheiros tutelares, juízes, promotores e toda-a-gente que, no máximo, em sua maioria, de sua posiçãosujeito, tem feito regurgitos dos bordões psiquiátricos hegemônicos postos, como, por exemplo, através da papagaiação dos enunciados do questionário Swanson, Nolan e Pelham-IV (SNAP-IV) ${ }^{\text {xvii }}$, já amplamente disseminado nas escolas e que é utilizado para ajudar na construção do diagnóstico de TDAH.

A psiquiatrização da educação, cuja condição de possibilidade encontra nas reconfigurações neoliberais do regime epistemológico moderno da Norma sua força maior, reativa as práticas do poder pastoral, pois convoca a ação do professor a realizar novas técnicas de inquérito, exame e confissão, através da criação de instrumentos que permitem uma triagem e uma primeira detecção a partir das salas de aula. 
Contudo, arrisco dizer que diferentemente do pastorado das sociedades disciplinares, o pastorado neoliberal não mais se encontra nas mãos do professor. Introduz-se um abismo educativo na desresponsabilização dos docentes quando a direção das condutas é pensada em termos de cérebro e não de relações/interações humanas. O poder pastoral passa, assim, a ser exercido por uma equipe multidisciplinar, legitimada pelos saberes psi-biomédicos hegemônicos da ciência moderna, bem como, especialmente, pelo controle dos psicofármacos.

Tal como no gesto pós-feminista de tirar o sexo da compreensão de natureza, também possamos nós implodir a noção de mente-cérebro como natureza. Não há nada a revelar na natureza do cérebro. A verdade do cérebro não é o seu desvelamento biológico, mas o seu empoderamento como estratégia de desenho da vida nas sociedades neoliberais, o que, juntamente com a naturalização do sexo, tem nos constituído continuamente refratários à alteridade.

\section{Referências}

BUTLER, Judith. Corpos que pesam: sobre os limites discursivos do sexo. In: LOURO, Guacira Lopes (Org). O Corpo Educado: pedagogias da sexualidade. 2. ed. Belo Horizonte: Autêntica, 2001.

CÉSAR, Maria Rita de Assis. Da escola disciplinar à Pedagogia do controle. Tese de doutorado. Universidade Estadual e Campinas. Faculdade de Educação. Doutorado em Educação, 2004.

COUTINHO, Karyne Dias. A emergência da psicopedagogia no Brasil. Tese de doutorado. Universidade Federal do Rio Grande do Sul. Faculdade de Educação. Programa de Pós-Graduação em Educação. Porto Alegre: URGS, 2008.

FOUCAULT, Michel. Microfísica do Poder. 17 ed. Rio de Janeiro: Graal, 2002.

FOUCAULT, Michel. Segurança, território, população. São Paulo: Martins Fontes, 2008a.

FOUCAULT, Michel. Nascimento da biopolítica. São Paulo: Martins Fontes, 2008b.

FOUCAULT, Michel. A vida dos homens infames. In: Ditos \& Escritos. Vol. IV. Estratégia, PoderSaber. 2. ed. Rio de Janeiro: Forense Universitária, 2010, p.203-222.

JERUSALINSKY, Alfredo; FENDRIK, Silvia (Orgs.). O livro negro da psicopatologia contemporânea. 2. ed. São Paulo: Via Lettera, 2011.

LOPES, Maura Corcini. Políticas de Inclusão e Governamentalidade. Educação \& Realidade, V. 34, n. 2 , p. 153-169, mai./ago. 2009.

LOPES, Maura Corcini; VEIGA-NETO, Alfredo. Inclusão, Exclusão, In/Exclusão. Revista Verve, n. 20, 2011, p. 121-135.

MOYSÉS, Maria Aparecida Affonso; COLLARES, Cecília Azevedo Lima. O lado escuro da dislexia e do TDAH. In: FACCI, M. G. D.; MEIRA, M. E. E. M. (Orgs.). A exclusão dos incluídos. 2. ed. Maringá: EDUEM, 2013a.

MOYSÉS, Maria Aparecida Affonso; COLLARES, Cecília Azevedo Lima. Medicalización del comportamiento y del aprendizaje. Una coartada para el uso de la violencia contra niños y adolescentes. In: DUEÑAS, G; KAHANSKY, R; SILVER, R. (Orgs.). Patologización de la Infancia. Problemas y desafíos 
en las aulas. 1. ed. Buenos Aires: Noveduc, 2013b.

MOYSÉS, Maria Aparecida Affonso; COLLARES, Cecília Azevedo Lima. Medicalização: o Obscurantismo Reinventado. In: COLLARES, Cecília Azevedo Lima; MOYSÉS, Maria Aparecida Affonso; RIBEIRO, Mônica Cintrão França (Orgs.). Novas capturas, antigos diagnósticos na Era dos Transtornos. 1. ed. Campinas: Mercado de Letras, 2013c.

MOYSÉS, Maria Aparecida Affonso; COLLARES, Cecília Azevedo Lima. Dislexia y TDAH: Dónde están las evidencias? In: UNTOIGLICH, G. (Org.). En la infancia los diagnósticos se escriben en lápiz. Consecuencias de la patologización de las diferencias en la clínica y la educación. 1. ed. Buenos Aires: Noveduc, 2013d.

RAMOS do Ó, Jorge. Tecnologias de subjetivação no proceso histórico de transformação da criança em aluno a partir dos finais do século XIX. In: VEIGA-NETO, Alfredo; CASTELO BRANCO, Guilherme (Orgs.). Foucault: filosofia \& política. Belo Horizonte: Autêntica, 2011, p. 175-194.

SIERRA, Jamil Cabral. Marcos da vida viável, marcas da vida vivível: o governamento da diversidade sexual e o desafio de uma ética/estética pós-identitária para teorização politico-educacional LGBT. Tese de Doutorado. Programa de Pós-Graduação em Educação. Universidade Federal do Paraná. Curitiba: UFPR, 2013.

SILVA, Tomaz Tadeu da. As pedagogias psi e o governo do eu nos regimes neoliberais. In: (org.). Liberdades Reguladas: a pedagogia construtivista e outras formas de governamento do eu. 2. ed. Petrópolis, RJ: Vozes, 1999, p. 7-13.

Recebido em: 30/04/2020

Aceito em: 03/08/2020

Notas

\begin{abstract}
${ }^{\text {i }}$ Doutora em Educação (UFPR). Professora adjunta do curso de Cinema e Audiovisual da Universidade Estadual do Paraná (Unespar). Pesquisadora do Gilda - Grupo Interdisciplinar em Linguagem, Diferença e Subjetivação (UFPR/CNPq). E-mail: juabreunogueira@gmail.com Paraná. ORCID: http://orcid.org/0000-0001-6153-7571
\end{abstract}

ii Carta aos médicos-chefes dos manicômios. In: Escritos de Antonin Artaud. Porto Alegre: L\&PM, 1983.

iii Preciado (2008, p. 31-32). In: PRECIADO, Paul B. Testo Yonqui. Madri: Espasa, 2008.

iv Este artigo é uma síntese dos principais argumentos do Ato I de minha tese de doutorado intitulada "Discursos de Psiquiatrização na Educação e o Governo dos Infames da Escola: entre cifras de resiliência e acordes de resistência", defendida em 2015 no Programa de Pós-Graduação em Educação da Universidade Federal do Paraná (PPGE/UFPR), sob a orientação da Profa. Dra. Maria Rita de Assis César.

v Tal perspectiva é distinta de tendências ligadas à psicanálise ou à psiquiatria social comunitária, por exemplo, às quais a psiquiatria clássica esteve mais ligada. A psiquiatria reinante vai compreender o sofrimento psíquico como "transtornos mentais que serão diagnosticados a partir da presença de certo números de sintomas (identificados a partir de uma lista presente no 
manual para cada transtorno) e que devem estar na vida do sujeito por um intervalo definido de tempo. Além disso, a psiquiatria americana consolida-se como discurso hegemônico e o DSM [em cada última versão revisada] é atualmente referência mundial de diagnóstico dos transtornos mentais, globalizando o modelo psiquiátrico americano" (GUARIDO, 2007, p.154). In: GUARIDO, Renata. A medicalização do sofrimento psíquico: considerações sobre o discurso psiquiátrico e seus efeitos na educação. Educação e Pesquisa, São Paulo, v. 33, p. 151-161, jan./abr. 2007.

vi Ver, por exemplo, o trabalho organizado por Jerusalinsky e Fendrik (2011), numa compilação intitulada “O livro negro da psicopatologia contemporânea". Destaca-se, ainda e sobretudo, as potentes e mobilizadoras pesquisas de Maria Aparecida Moysés e Cecília Collares (2013a, 2013b, 2013c, 2013d), as quais ecoam em tantos outros trabalhos por serem referência na tarefa de desconstrução radical das proposições postas como científicas acerca das noções de transtornos mentais, especialmente quando estes referem-se às crianças e têm possibilitado o agigantamento da medicalização da educação.

vii Em minha pesquisa de doutoramento, envolvi-me com uma leitura semanal em arquivos de um centro de avaliação psicopedagógica/atendimento especializado público, durante aproximadamente 6 meses (fevereiro a agosto de 2014), localizado numa cidade da região metropolitana de Curitiba, Paraná. Chamei de prontuários as inúmeras pastas que arquivam os dados e históricos de avaliação psicopedagógica, médica e, inclusive, jurídica das crianças que são encaminhadas para avaliação e acompanhamento por apresentarem queixas escolares em relação às suas condutas/comportamentos.

viii É fato historicamente bastante novo entre nós o surgimento de centros de avaliação e atendimentos especializados (em suas diferentes denominações), os quais, potencialmente, foram criados, ao menos em quase todas as médias e grandes cidades brasileiras, na segunda metade dos anos 1990/início dos anos 2000 e praticamente todos vinculados a Departamentos de Educação Especial, embora se destinem, majoritariamente, às demandas da educação inclusiva, a atender a população infantil das escolas regulares. Não vou fazer uma genealogia de tais espaços (trabalho que, por certo, seria muito instigante), mas, ao adentrá-los nesta pesquisa, precisei pensá-los, foucaultianamente, como instituições - com práticas discursivas e tecnologias de governo dos corpos e da população - cujo surgimento é datado historicamente e somente possível porque se encontra com determinada ordem do discurso, com determinados jogos de verdade/saber e com determinados exercícios de poder, na ordem de uma determinada governamentalidade.

ix Nome ficcionalizado.

${ }^{\text {x }}$ Enunciado retirado do filme Mommy (2014).

xi Poeta é a sigla de "Programa Orientação Escolar para Alunos com Transtornos de Aprendizagem e/ou Transtorno de Déficit de Atenção e Hiperatividade", instituído por lei municipal. Nos termos deste decreto, têm direito ao acompanhamento no referido programa os alunos com laudo médico com o diagnóstico de Transtorno de Aprendizagem e/ou TDAH, que estão matriculados em Escolas Públicas e que frequentam o Ensino Fundamental.

xii Centro de Atenção Psicossocial - Álcool e Drogas.

xiii Segundo o site do Ministério do Desenvolvimento Social e Combate à Fome (www.mds.gov.br), o CRAS - Centro de Referência da Assistência Social - "é uma unidade pública estatal descentralizada da política de assistência social sendo responsável pela organização e oferta dos serviços socioassistenciais da Proteção Social Básica do Sistema Único de Assistência Social (SUAS) nas áreas de vulnerabilidade e risco social dos municípios e DF.

${ }^{\text {xiv }}$ Muitos estudos têm demonstrado que a escola moderna, mais fortemente a partir do século XIX, esteve aliançada com os discursos psi. Sem a pretensão de esgotar a citação dos inúmeros trabalhos que debruçam-se sobre a relação discurso pedagógico e discursos psi, aproprio-me, nesta pesquisa, especialmente das abordagens de Silva (1999), César (2004), Ramos do Ó (2011) e Coutinho (2008).

${ }^{\mathrm{xv}}$ Frequentemente, os laboratórios Novartis, fabricante da Ritalina® e Janssen Cilag, uma subsidiária da Johnson \& Johnson, fabricante do Metilfenidato conhecido por sua denominação comercial Concerta®, bem como a Shire, que é "uma companhia biofarmacêutica global [...] que especializou-se nas áreas de déficit de atenção e hiperatividade e doenças genéticas" (texto presente no próprio site da Shire-Brasil), aparecem como apoiadores/parceiros/financiadores de procedimentos de conscientização e implementação de protocolos de diagnóstico e tratamento, cujos propositores são associações de defesa das crianças com transtornos mentais (como a Associação Brasileira do Déficit de Atenção - ABDA) e o Estado.

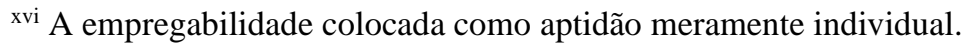

xvii Este questionário foi construído a partir dos sintomas do Manual de Diagnóstico e Estatística - IV Edição (DSM-IV) da Associação Americana de Psiquiatria com a tradução validada pelo GEDA - Grupo de Estudos do Déficit de Atenção da UFRJ 
e pelo Serviço de Psiquiatria da Infância e Adolescência da UFRGS. No site da Associação Brasileira de Déficit de Atenção ABDA, por exemplo, é possível ter acesso ao questionário. Em dado momento diz o portal: “[...] Você também pode imprimir e levar para o professor preencher na escola" (grifos meus). Ver: http://www.tdah.org.br/sobre-tdah/diagnostico-criancas.html 